\title{
Health Impacts of a Traditional Illicit Brew (Kaanga) Consumed in Meru County, Kenya
}

\author{
Atuna Titus Gitari ${ }^{1}$, Osano Aloys ${ }^{1}$, Bakari Chaka ${ }^{1 *}$, Bulitia Godrick ${ }^{2}$
}

\author{
${ }^{1}$ Department of Mathematics and Physical Sciences, Maasai Mara University, Narok, KENYA \\ ${ }^{2}$ Department of Economics and Human Resource Management, Maasai Mara University, Narok, KENYA \\ *Corresponding Author: bakarichaka@yahoo.com
}

Citation: Gitari, A. T., Aloys, O., Chaka, B. and Godrick, B. (2021). Health Impacts of a Traditional Illicit Brew (Kaanga) Consumed in Meru County, Kenya. European Journal of Environment and Public Health, 5(1), em0065. https://doi.org/10.29333/ejeph/9146

ARTICLE INFO

Received: 9 Jul. 2020

Accepted: 31 Aug. 2020

\begin{abstract}
Kaanga brew is a common illicit liquor from Meru county in Kenya. Popularity of this brew has been growing and is religiously passed down from one generation to the next. The substrates, preparation process and additives used in making it are unhygienic and toxic. As a result, numerous social and health effects have stemmed from its consumption. This study aimed at analyzing the health impacts arising from consumption of Kaanga brew in Meru county, Kenya. A cross-sectional design of study was employed. The research tools used included questionnaires, interviews and observations. Descriptive statistics was used to analyze and present the findings. The results indicated that popularity of this brew was mainly because it was cheaper than other alcoholic beverages. Its consumption was projected to continue for a long period, if strict intervention measures are not taken. The additives used, such as battery acid, methanol and dry cells were indeed toxic for human consumption. Several social effects which had public health effects (such as irresponsible sex activities), by extension were experienced from the consumers. Kaanga brew had significantly more chances $(P>0.05)$ of causing health effects compared to the other brews. Some of the direct health conditions arising from its consumption include loss of vision, memory and appetite, inflammation and regular stomach upsets. 80\% of the respondents had witnessed or heard of a death case caused by the brew.
\end{abstract}

Keywords: Kaanga illicit brew, Meru county, health impacts

\section{INTRODUCTION}

Despite civilization of most socio-economic and lifestyle patterns in Kenya, traditional alcoholic beverages have strongly persisted. The preference for these brews is more in rural areas and urban suburbs (downtowns). The brews are unlicensed and unstandardized. Several factors have been attributed to preference of these brews over other standardized alcoholic beverages such as wines, spirits, gin and beer. Some of the reasons include their traditional/indigenous nature, availability in rural areas, pocket friendly and high total ethanol content.

The populace and by extension production of illicit brews is largely governed by consumers perception. The catch is to satisfy or appease consumers to make them regular, if not permanent clients. This will in turn generate more revenue to them. Since the brews are not censored or standardized, the brewers use all possible methods to prepare these alcohols. The quality of any brew is determined by the preparation process and additives added (Iglesias et al., 2014). Preparation of illicit brews follows a similar scientific path to that of other alcoholic beverages (Luu et al., 2014, p. 731), but with other non-scientific, unhygienic psychologically-inspired additives which makes the drinks unsafe for human consumption.

The first step in preparation of the brews is fermentation of substrates (usually maize flour and sorghum). This process takes about two days after which the water is drained from the malt and fresh water, sugar, honey or molasses is added to aid in fermentation. Battery (lead-acid) acid is often added to hasten the process. After about one week, the mixture is filtered and the liquid concoction is distilled in river beds. This aims at refining the brew to eliminate contaminants and be left with ethanol (Luu et al., 2014, p. 731; Ohimain 2016, p. 1607). However, due to the inaccuracy of reagents used, other compounds with similar boiling points to ethanol find their way into the final brew. Other additives are then added to increase ethanol content (monitored by bitterness of the brew) and lure more customers. Some of these additives include used up dry cells (Leclanché cells), sanitary towels, women's inner garments and coins. These additives introduce toxic compounds such as ligands and heavy metals into the brew. Poor fermentation and distillation process introduce toxic compounds such as methanol, aflatoxins, polycyclic aromatic 
hydro-carbons (PAHs), formaldehyde and other volatile compounds in the brew (Ohimain 2016, p. 1607; Okaru et al., 2017, p. 89; Zamani et al., 2019, p. 56).

Consumption of these uncensored chemicals cause numerous health complications to the consumers. The first effect is usually addiction. The consumers body cannot function without the liquor and have to take it to 'jump-start' their bodies. Food appetite slowly fades away further weakening the consumers immune and growth system. The high acidity levels in the brew corrode the consumers lips and gastro-intestinal tract (Burbige et al., 1984). The consumer will appear to have red lips due to this corrosion. For some, their gums loosen and teeth fall out (Saini et al., 2013; Shekarchizadeh et al., 2013). Continuous corrosion of gastrointestinal tract lead to Gastroesophageal reflux disease (GERD) and esophageal cancer (Anand and Kalra, 1996; Chen et al., 2010). Volatile compounds and aldehydes in the brew are carcinogenic in nature (Humia et al., 2019, p. 1568). Prolonged consumption of this brews cause liver diseases owing to the high acidity of the brew (Bruha et al., 2012; Gordon, 2001). Other common diseases include pancreatitis, ulcers, brain disorders and heart diseases (Obad et al., 2018, p.81). Methanol consumption leads to vision loss (Manuchehri et al., 2015). At high doses, the victim can easily die (Manuchehri et al., 2015).

The Kaanga brew is not an exemption to these public health effects. Most of the health effects resulting from alcohol consumption as mentioned above are also realized by drunkards in Meru region. A good number of the drunkards are already addicted to the brew. The brew is so lethal such that it has been christened 'kill me quick' for its health impacts. Several drunkards of Kaanga have died due to liver cirrhosis. This problem arises due to liver corrosion replacing liver cells with scars and therefore the liver cannot perform normally (Schuppan and Afdhal, 2008). The rate of transmission of HIV/AIDS and other sexually transmitted infections (STIs) in Meru region is also high. Majority of the residents agree that the diseases are transmitted by promiscuous behavior of Kaanga drunkards. Most of the drunkards do not use protection tools to avoid STIs and unplanned pregnancies. Regular fights by drunkards are attributed to numerous physical deformities and bruises on their bodies. One can easily identify a Kaanga drunkard from a crowd due to these body deformities and bruises. The drunkards also pose a 'redlips' trademark resulting from lip corrosion by Kaanga brew. On several occasions, there has been vision loss and death cases after consumption of the brew. This arises from the methanol laced in Kaanga brew. Use of dump maize flour and poor preparation process imparts aflatoxins in Kaanga brew. It is therefore not surprising that the rate of liver cancer in the county has been increasing; especially for Kaanga brew consumers.

There are several researches that have been conducted on the impacts of traditional liquor and illicit brews in Kenya. Most of these studies have been based on the general impacts of the alcohols on the consumers and their immediate society. The common brews studied include Muratina, Chang'aa and Busaa (Ohimain, 2016, p. 1607; Papas et al., 2010; Takahashi et al., 2017, p. 175). Little has been documented concerning Kaanga brew. The Kaanga illicit brew in Meru county, Kenya is one of the notorious brews associated with these health effects. Its populace in the region has been growing over the years, forcing the brewers to invest newer additives to continue luring the customers. On the other hand, health cases and deaths arising from its consumption have also been increasing. Most of the scientific studies conducted on illicit brews have focused on the contaminants present in these brews likely to cause health problems; such as aflatoxins, volatile compounds, methanol and alcohol content (Ohimain 2016, p. 1607; Papas et al., 2010). However, there is a gap in the actual (quantitative) health issues/diseases arising from consuming illicit brews. This study aimed at investigating the health impacts associated with consumption of Kaanga brew. This data is crucial for administrators and public health officials in the region as it can guide them while making policies to solve the menace.

\section{RESEARCH METHODOLOGY}

\section{Design of Study}

A cross-sectional design of study was followed, with the study being conducted in the month of June, 2018. This type of study was preferred for several reasons. There was need to concentrate their study focus on one point; the epicentre of Kaanga brew (Meru county). This would give a better image of the situation at hand rather than merely working with a bigger region and get scanty findings. The objective of the study was to assess the public health effects caused by consumption of Kaanga brew which suits this study design well. From the objective, only descriptive findings (health impacts caused by the brew) were required. The design was thus viable in collecting this information without necessarily tracking down on the science involved in causing the effects after consumption of the brew. The study was done in various regions of Meru county, Kenya (coordinates $0.3557^{\circ} \mathrm{N}$, $37.8088^{\circ} \mathrm{E}$ ) as outlined in Figure 1 . The study focused in five major setups of the county with high population i.e. Timau, Meru, Kianjai, Maua and Nkubu. From each of these points, a rural area and an urban suburb could be chosen. These formed two study sites for each of the five setups totaling ten study sites. Data was collected using questionnaires (see Appendix 1). Qualitative and descriptive analysis was conducted due to the nature of the research at hand. The target population was the brewers and consumers of the brew.

\section{Sampling Techniques}

Despite having so many casualties of illicit brew in Meru county, it was unrealistic to get the respondents of all the members due to time and budget. Stratified sampling was therefore more suitable for the study. Two strata were used i.e. consumers of the brew and the brewers (including the sellers). The consumers of Kaanga were chosen because of their ability to give first-hand experience and health conditions resulting from the brew. The brewers of Kaanga brew were involved since they were presumed to consume the brew as well as had witnessed many health conditions arising from their clients. This is because they have a lot information about their clients. Some of the brewers are also victims of irresponsible sex with the consumers leading to STIs and other health impacts. For both strata, purposive sampling was used. Priority was given 


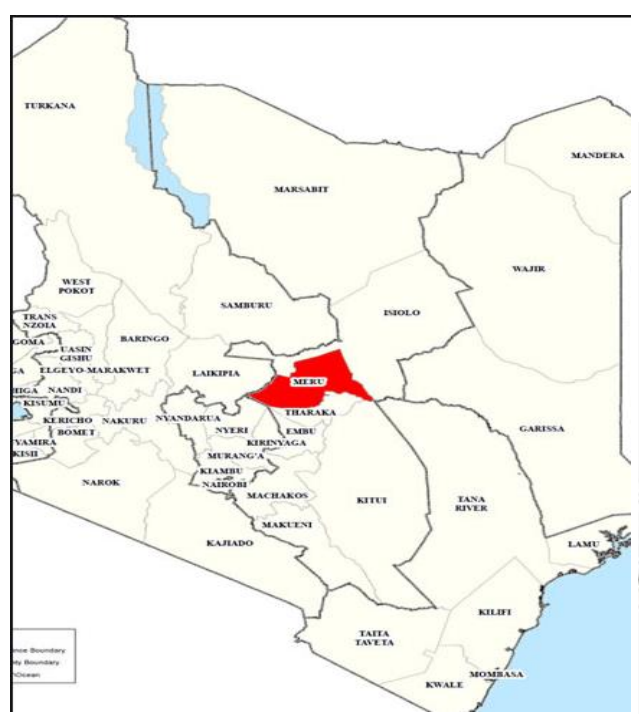

(a)

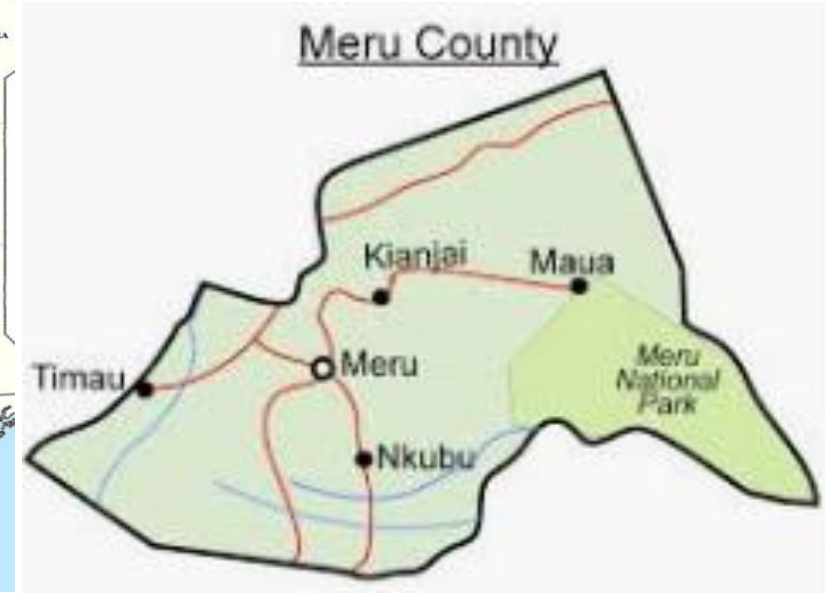

(b)

Figure 1. The study location. The study was conducted in Meru county in Kenya (a) in the five major towns of the county (b) Source: Meru.go.ke (2020). (Figure 1a) Learn.e-Limu.org (2020) (Figure 1b)

on sober and non-violent respondents. These traits were informed by the local research coordinators and interpreters who had known the respondents for some time. Respondents who appeared to be suffering from a health condition (by simply observing their bodies) were also prioritized. However, the local research coordinators and interpreters were also involved in determining the viability of these respondents. The respondents were picked from their homes, not the drinking den. In cases where respondents could only be found in the drinking den, only sober respondents were picked. This was informed by determining whether they had consumed liquor and assessing them before any sampling could proceed. The baseline of this method was to get credible results which could only be obtained from sober respondents.

\section{Sample Size}

The study area (Meru county) was divided into five major clusters, based on human population and development i.e. Timau, Meru, Kianjai, Maua and Nkubu. Each of the clusters was then divided into two sub-clusters; rural and urban downtowns. This formed a total of 10 sampling clusters. Eight samples were picked from each of the 10 sub-clusters. This yielded 80 samples in total. At each study site, two samples were picked from the brewers while six were picked from the customers. The consumers were given a higher preference over the consumers since they were the major victims. They were the direct casualties of Kaanga brew. The brewers were however involved in the study for their experience with their clients and their health conditions.

\section{Research Questionnaires, Interview and Observation Guides Used}

The study involved use of questionnaires, interviews and observation for data collection. Questionnaires were given out to literate respondents. The questionnaires were unstructured and had both open ended and closed research questions. The questionnaires were divided into 2 main sections i.e respondents biodata section and a section involving Kaanga brew and public health information (See Appendix 1). The researchers guided the respondents on the areas needing interpretation or any other assistance. For illiterate respondents, the researchers took the respondents through the study via interview guides. The structure and content of the guides was similar to that of the questionnaires. Both the questionnaires and interview guides were designated to collect the same type of data i.e. the biodata of respondents, their affiliation to Kaanga brew and health impacts arising from consumption of the brew. Observation guides were used to help assess some of the situations that could easily be noticed. There was no clear structure or number of research items in an observation guide but rather researchers' opinion on notable features of respondents, Kaanga brew or health impacts of the brew. Observation guides were quite instrumental for assessing physical body bruises and deformities of the affected respondents.

\section{Validity and Reliability of the Research Guides}

Questionnaires were quite reliable since they were easy to administer and encouraged confidentiality thus, reducing biasness. Interviews enabled the use of open-ended questions that aided in acquiring reliable findings and more detailed answers. Both were subjected to the test-retest reliability method to check for their consistency in results after a duration of 14 days. A group of 10 respondents (volunteers) was used. There was a similarity index of $71 \%$ in the results at the two instances of testing. Observation also ensured gathering of reliable data. The 10 respondents were also assigned with the same task and a $63 \%$ similarity index observed. A face validity of the research guides was conducted by 5 volunteers. A pilot study was then conducted to determine the validity of the data collection instruments used. Each of the 18 initial distinct research questions in the questionnaire guide (excluding bio-data section) was assigned to 5 different respondents. In total, there were 90 respondents (volunteers). The data was then debugged and the minimum and maximum values recorded. After a critical analysis check, 4 questions were found to be confusing and leading. The questions are; (i) What factors make you not to consume Kaanga brew? (ii) Have 


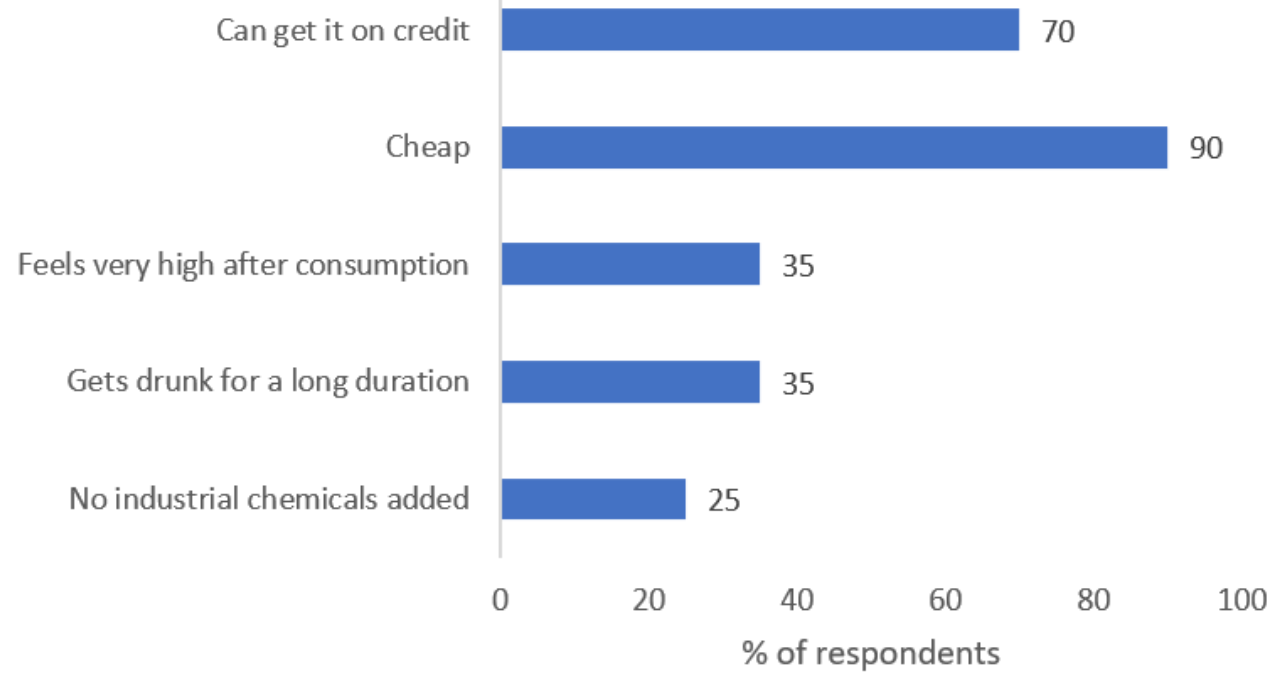

Figure 2. Factors determining choice of alcoholic beverage consumed

you witnessed preparation of the brew? (iii) Rank the order of social factors affected by Kaanga brew. (iv) Rank the types of health effects suffered due to consumption of the brew. These questions were plucked out. The ultimate validity score was thus $14 / 18$ (78\%) and the outcomes were found to strongly favor the use of these research guides.

\section{Data Analysis}

The data collected was analyzed and presented using descriptive statistics. The data collected was analyzed using Ms Excel (2016). For the significance levels, a confidence level of $95 \%$ was used based on the sample size used.

\section{RESULTS AND DISCUSSIONS}

\section{Factors Leading to Preference of Kaanga Brew Over Other Standardized Alcoholic Beverages}

Majority of alcohol consumers in Meru county preferred Kaanga illicit brew over the conventional standardized brews for its cheap nature. The consumers indicated that their daily wages averaged Ksh. 300. Ksh. 100 was usually reserved for alcohol and tobacco drinking (3 cups of Kaanga brew each at Ksh. 30 and tobacco at Ksh. 10). The consumers also confirmed that it was easier to get Kaanga brew on credit unlike other standardized alcoholic drinks which demanded instant pay. This made them prefer the drink as a cheap alternative to keep them busy after work while making them temporarily forget their problems. The consumers of Kaanga brew were also not cautious of the amount of money to be spent in hospital due to health effects resulting from the brew. All they cared was getting drowsy and merry at that instant. Unlike the conventional standardized alcoholic beverages, the consumers indicated that Kaanga brew had a special effect which increased the effective drowsiness period. The drunkards did not bother about the nature of this 'special effect' chemicals and how they affected their health status. This 'special effect' kept them drunk and thus merrier for several hours after the actual consumption of the brew. $35 \%$ of the consumers also indicated that the drowsiness level of Kaanga brew was higher than that from other brews. This can be attributed to chemical compounds in the brew which arouse the nervous system (Ferré and O'Brien, 2011) past the safe ethanol concentration levels. Presence of concentrated methanol and unrefined ethanol in the brew are responsible for this drowsiness effect (Tulashie et al., 2017, p.14). Its consumption leads to blindness and death. These chemicals later lead to several ailments (Woteki and Thomas, 1992). The ethanol level in the brew is past the permissible health value due to lack of standardization by government agents. The factors affecting choice of alcoholic beverages in Meru county are illustrated in Figure 2.

The residents also believed that Kaanga illicit brew was safer than other wines and spirits which had industrial chemicals. The consumers were of the opinion that the industrial alcoholic beverages were added chemicals to regulate the available ethanol content. This was against their desire for brews with high ethanol concentration; irrespective of their health repercussions.

\section{Unhealthy Additives Used in Preparation of Kaanga Brew}

Majority of the consumers and brewers attested that the main factors leading to use of the additives were to attract customers while increasing ethanol content. Some of the additives used did not have any scientific backgrounds. However, the brewers attested that use of such additives (e.g. five-shilling coin) have supernatural powers of attracting clients. They believed that these chemicals had little or no health effects and that Kaanga brew had only little additives as illustrated in Table 1 . The brewers who prepare Kaanga also confirmed that their brew had some local contaminants which they cannot categorize as chemicals. The respondents believed that other wines and spirits have foreign chemicals that increase ethanol content. This triggers them to try and invent new additives to minimize the competition. $85 \%$ of the respondents believed that women inner garments lured male clients to consume the brew. This is oblivious of the body contaminants present in women bodies (Jaishankar et al., 2014). Women sweat more than men as well as excrete other body fluids which at times permanently stain their inner garments (Baker, 2019). The garments therefore have a lot of 
Table 1. The common types of additives present in Kaanga brew

\begin{tabular}{clc}
\hline Additives & \multicolumn{1}{c}{ Role } & \% Respondents witnessed \\
\hline Five-shilling coin & Attract customers & 90 \\
\hline Women's inner garment & Attract customers & 85 \\
\hline Yeast & Hasten fermentation & 85 \\
\hline Methanol & Concentrate ethanol & 45 \\
\hline Battery acid & Hasten fermentation & 60 \\
\hline Dry cells & Impart bitter taste in the brew & 45 \\
\hline
\end{tabular}

toxic compounds which are passed on into the brew and later consumed. These toxic compounds are responsible for some of the health effects caused the brew. $85 \%$ of the respondents agreed to the use of yeast in hastening fermentation process. This is a normal ingredient with scientific backing for its ability to accelerate anaerobic digestion of biomass substrate (Zupančič et al., 2017). Little doses of methanol were also added (as witnessed by $45 \%$ of the respondents) to concentrate the brew (Ohimain 2016, p. 1607). Methanol has close chemical properties with ethanol. However, methanol is more toxic then ethanol (Noor et al., 2020, p. 6), especially at high concentrations. Methanol has the ability to induce permanent neurological disfunction and irreversible blindness (Jahan et al., 2015). $60 \%$ of the respondents had witnessed addition of battery acid to catalyze fermentation process. Like other mineral acids, sulfuric acid, the main recipe in battery acid can degrade biomass of ligno-cellulosic nature to fermentable sugars (Oriez et al., 2019, p. 4273). However, the process is not always regioselective and yields numerous by-products (Kumar and Sharma 2017, p. 7). The acid is also added in small amounts in a typical industrial set-up, which might not be the case in preparation of Kaanga brew. High doses of unreacted acid and other acid products end up in the final brew. These products impart some bitter taste into the brew which the consumers confuse with high ethanol content. Consumption of sulfuric acid corrode body tissues, create stomach holes and other ocular injuries (Singh et al., 2003). $45 \%$ of the respondents agreed with addition of dry cells into the brew (Table 1). They indicated that these cells concentrate ethanol while imparting some bitter taste, confused to be high ethanol content. Dry cells have other compounds with human effect present (Tchounwou et al., 2012). For example, the cells are rich in manganese dioxide powder which can oxidize ethanol and other alkanols to their respective aldehydes and ketones (Huang et al., 2012). This process is more likely to occur during distillation process (high temperature) or in presence of sulfuric acid (catalyst). Several aldehydes and ketones are carcinogenic. Formaldehyde is a lethal aldehyde with numerous side effects to the human body (Fischer, 1905).

\section{Consumption Duration and Trends in Consumption of Kaanga Illicit Brew}

The duration of consumption of Kaanga brew increased linearly with the age of the respondents. This implies that the trend of consumption has been religiously passed on like a rite in Meru county. Even with more market penetration of other commercial brands of alcoholic beverages, the popularity of Kaanga brew have withstood. Young men are introduced into the brew immediately after initiation into adulthood. Here, they are viewed as full grown adults who can consume liquor and smoke tobacco without any alarm. This culture has been gradually and consistently inculcated into Meru youth. Consumption of Kaanga brew is therefore not likely to end soon if this practice is not brought to an end. Figure 3 illustrates how the populace of Kaanga brew has been passed down religiously, from old men above their working years to young school-going lads.

Lack of any censoring, licensing or standardization of illicit alcohol (such as Kaanga brew) has also contributed to its persistent availability (Sudhinaraset et al., 2016). The brewers have developed tactics to hide the brew when government authorities or health personnel visit. When these two agents know of its presence, they are bribed to allow its consumption. From Figure 3, Kaanga brew is likely to be present in the region for the next several generations if strict measures are not put to curb it. By extension, the health effects arising from its consumption will also be realized for as long as the brew is in existence.

\section{Preference of Some Unhealthy Properties of the Illicit Brew}

Kaanga brew was available in two brands (of high and low ethanol concentration). Preference of the two was mainly governed by the consumers spending power. Highly concentrated brews were for the 'richer' consumers. These brews had more total ethanol concentration thus different characteristics from the other one. Most of the consumers of Kaanga brew loved getting drowsy quickly and for a longer duration. This would allow them to forget their troubles for a faster and for a longer duration. The slightly richer consumers also loved to get drowsy quickly and save time and money for other functions. High ethanol content is a critical factor for this to happen (Paton, 2005). The consumers did not care on the effect of high ethanol content on their health The consumers and brewers have all mastered determination of how Kaanga brew with high ethanol concentration appears. Several factors including its smell, color and taste inform them (Figure 4). The price of the brew also informs the buyers whether the brew is concentrated in ethanol or not (Figure 4).

Kaanga brew with high ethanol concentration has a harsh taste with a burning sensation. The brew also easily corrodes the mouth and stomach lining during consumption. Most of the clients who consume Kaanga brew with high ethanol content admitted to having tears fall out of their eyes upon completion of a pint-ful of the brew. This brew has a more clearer appearance due to high ethanol content. Kaanga brew with low ethanol content have more substrates (muna/machicha). These substrates are laced with other organic and inorganic residues that can affect the health of its consumers. The consumers reported that Kaanga brew with high ethanol content had a sharp acrid and rancid smell, instead of the rather gentle odor. This indicated 


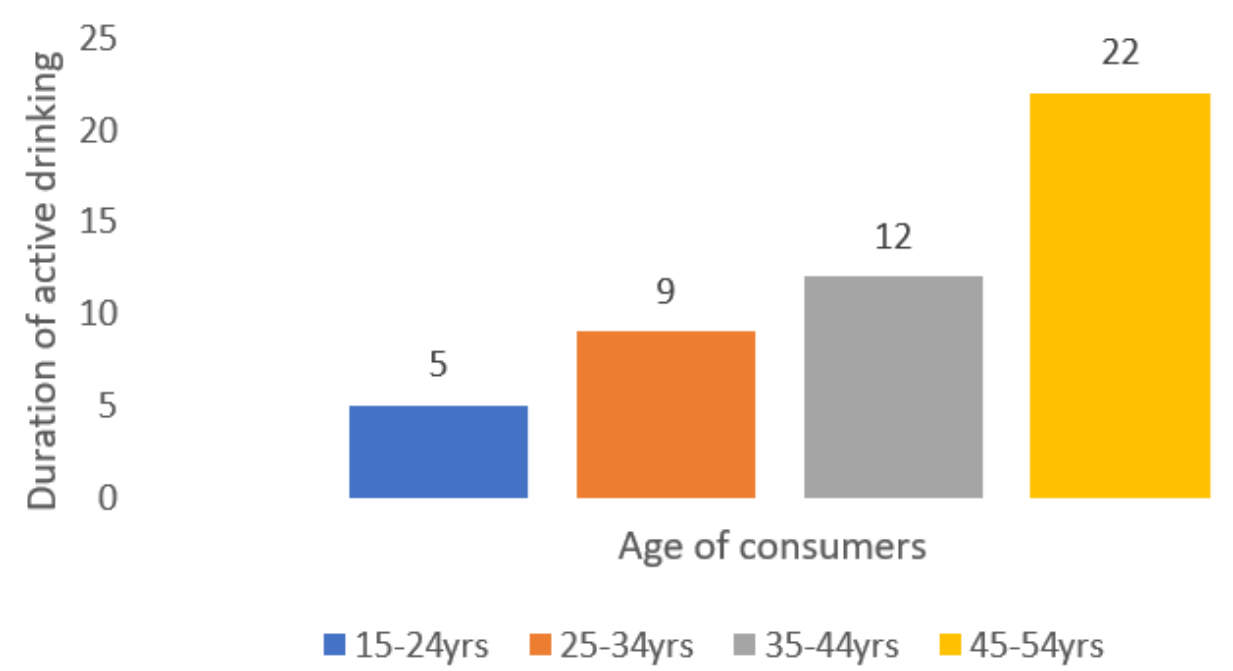

Figure 3. Longevity of Kaanga brew amongst the consumers in Meru county

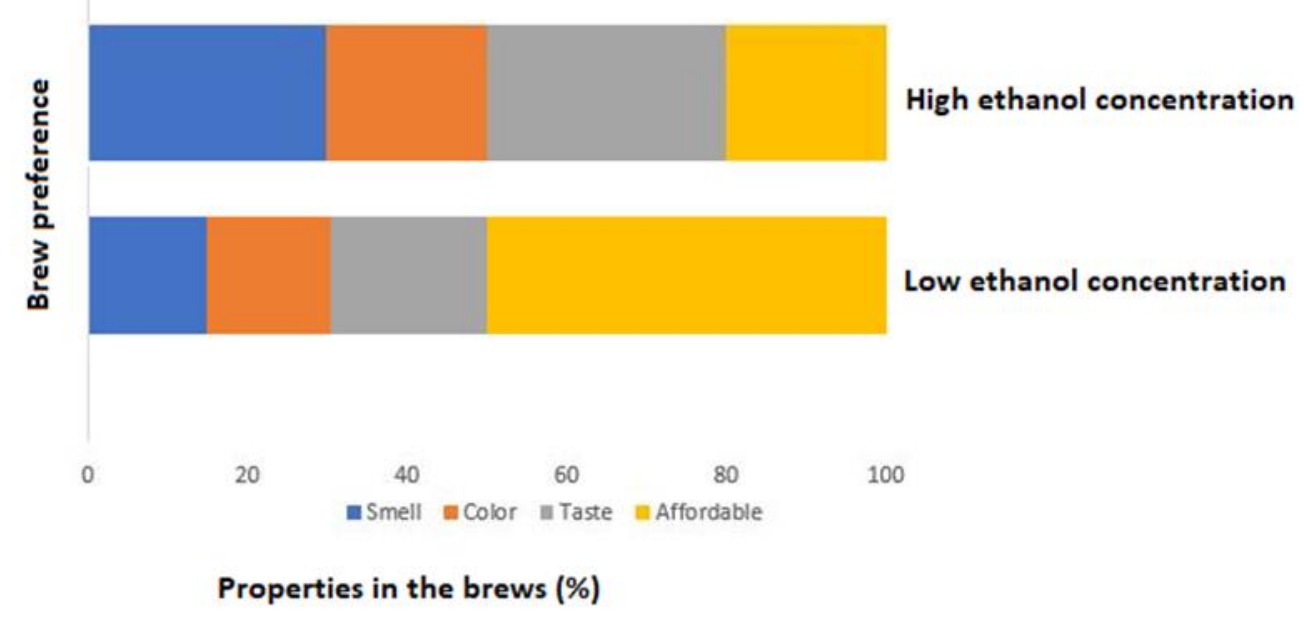

Figure 4. Factors used to determine the level of ethanol in Kaanga brew

contamination with organic acids (Mika and Kazushige, 2011; Suiryanrayna and Ramana 2015, p. 45). This is an indicator of oxidation of the ethanol to ethanoic acid, possibly due to presence of sulfuric acid and manganese dioxide (Huang et al., 2012). Lower prices are intended for more dilute (less concentrated brews). This is because less of their 'precious additives' such as battery acid and methanol have been used for its production. These products have also been serially diluted and have less demand, therefore sold at cheaper prices.

Social Consequences of Consuming Kaanga Brew with an Effect on the Health of its Consumers

Social ties have been known to influence multiple health behaviors including mental health, fertility and mortality rate (Short and Mollborn, 2015). Like other alcoholic brews, Kaanga brew was also alleged to cause several social effects to the society and family. Some of these effects have far-reaching consequences that later on effect the general health of the victims. For example, $87 \%$ of the respondents admitted to causing family wrangles. These wrangles end up in violence whereby injuries result and the casualties develop minor or major health complications. Most respondents also admitted to using vulgar language which later leave the recipients of the communication stressful (Kourkouta and Papathanasiou, 2014). Accumulated stress resulting from vulgar language leads to depression (Mariotti, 2015). $72 \%$ of the respondents confirmed that they could not fulfill their conjugal responsibilities due to consumption of Kaanga brew. The respondents were either too drunk but willing to be able to fulfill the activity or too violent and vulgar to do it. Others admitted that continuous consumption of the brew reduced their sex drive (libido power). Most of the respondents consume the brew without taking any food prior. This dilapidates their body such that any intentions to fulfill conjugal responsibilities after consumption of the brew is null and void. $63 \%$ of the respondents admitted to having promiscuous behavior after its consumption. The respondents had a lot of sex zeal but little energy to fulfill it. Several respondents, especially the female brewers admitted to sleep with several men after consuming the brew. Most of the men also admitted to sleep with other unlawful partners after its consumption. This is because their thinking capability is partially impaired by the consumption (Sullivan et al., 2010). Figure 5 illustrates the social effects arising from consumption of Kaanga brew. 


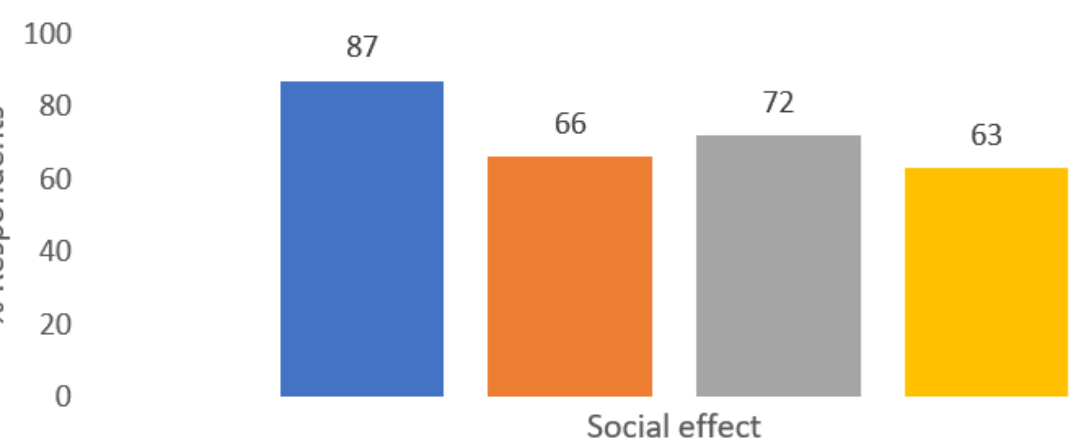

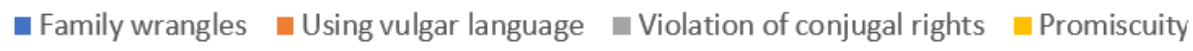

Figure 5. Social effects which by extension have public health effects arising from consumption of Kaanga brew

Some respondents alleged that the women inner garment put as additives led them to these behaviors. Sexually transmitted infections increase from these behaviors since the respondents are too drunk to care about protection. Some bastards have also resulted from these promiscuous behaviors. These children end up growing in limited health care and are subject to malnutrition as well as other misfortunes.

\section{Effects of Kaanga Illicit Brew on Health of Consumers}

According to the respondents, Kaanga brew was the most lethal alcoholic beverage with a higher potential of causing health effects. $70 \%$ of the respondents indicated that Kaanga brew caused health problems after consumption, 15\% more than other traditional brews. This difference can be justified by the additives added to increase ethanol content in the brew, unlike in other brews where these additives are not added. The health effects resulting from Kaanga brew stem not only from the toxic additives added, but also from the preparation process of the brew. Wort-making (termed as muna or machicha in the local dialect), is carried out in sub-standard reactors. The process is not validated and the maize flour used doesn't undergo any quality control. Therefore, chances of aflatoxins ending up in the wort are high (Inoue et al., 2013). Kigen et al., (2015, p.59) confirmed presence of various mycotoxins compounds in preparation of traditional Kenyan brews undergoing fermentation such as Mursik, Busaa and Chang'aa. Amines such as ethylamine and methylamine also result from reaction of ammonia with ethanol and methanol respectively (Klinkenberg and Hartwig, 2011). These compounds are toxic to the human body in many ways. Most of the respondents confirmed that standardized wines and spirits as well as other licensed alcoholic beverages contribute about only $30 \%$ to health effects (Figure 6a).

Even then, they said that the effects from these brews cropped up after a long period of continuous consumption (about 10 years). From Figure 6a, there is a large disparity in the probability of health effects between Kaanga brew and the other alcoholic beverages. Kaanga brew can be termed as significantly more toxic compared to the rest $(P>0.05)$. However, these effects can be reduced by eating some food before, during or after consumption of the brew as illustrated in Figure 6b. Eating meat while consuming the brew was cited as a good mitigation remedy to prevent the health effects $(85 \%$ of respondents). Most of the respondents indicated that meat and cereals ( $75 \%$ of respondents) minimize the hangover remedies from Kaanga booze. Piasecki et al., (2010) indicated that the extent of alcohol hangover is directly proportional to the calories present in the brew. In this regard, owing to the nature of substrate used in preparation of Kaanga brew, the calories are likely to be quite high. Apart from proteins, meat has high levels of vitamin $\mathrm{D}$ which give a testosterone boost necessary to mitigate alcoholic effects (Afeiche et al., 2014). Cereals and nuts rejuvenate the body by supplying the body with omega-3 fatty acids required in counteracting alcohol effects (Brenna et al., 2015, p. 117). 40\% of the respondents indicated that eating a balanced diet before consumption of Kaanga brew also mitigated its side-effects.

\section{Direct Health Conditions Arising from Consumption of Kaanga Brew}

Several health conditions were believed to be brought about by consumption of Kaanga brew as illustrated in Figure 7. Loss of appetite was the most notable effect, which was significantly higher than the others $(P>0.05)$. Appetite is controlled by Agouti-related peptide cells (AGRP) found in the brain (Sohn, 2015). These cells become chemically blocked by alcohol thus hindering communication to the brain concerning food (Sohn, 2015). 70\% of the respondents confirmed that inflammation was a problem related to Kaanga brew. Inflammation is triggered by some proteins and immune cells activated by endotoxins (Chen et al., 2017). These compounds result from overgrowth of bacteria in the human gut. The process is accelerated by alcohol. Illicit brews such as Kaanga which have other numerous unhygienic contaminants are a perfect recipe for nurturing gut bacteria. Chronic inflammation can cause cancer (Coussens and Werb, 2002; Singh et al., 2019). 65\% of the respondents indicated to suffer from memory loss after consuming Kaanga beer. Due to memory loss, most of the social effects conducted while drowsy such as sexual immorality could not be recalled by the victims.

Due to the acidic nature of the brew, $55 \%$ of the respondents who consumed Kaanga brew had their lips eroded. Some of their lips had reddened while others were swollen due to constant rubbing as the lips itched. $45 \%$ of the respondents had swollen cheeks while a similar number of respondents experienced stomach upsets. Stomach upsets resulted from the myriad of contaminants in the brew. This condition was more frequent to new consumers of the brew. These upsets made the consumers to puke out earlier eaten food further 


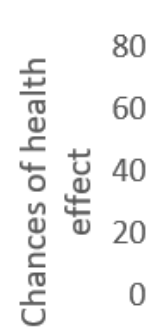

70

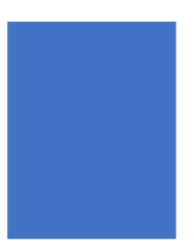

55

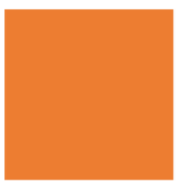

30

Type of brew

- Kaanga $\quad$ Other traditional $\quad$ Commercial

(a)
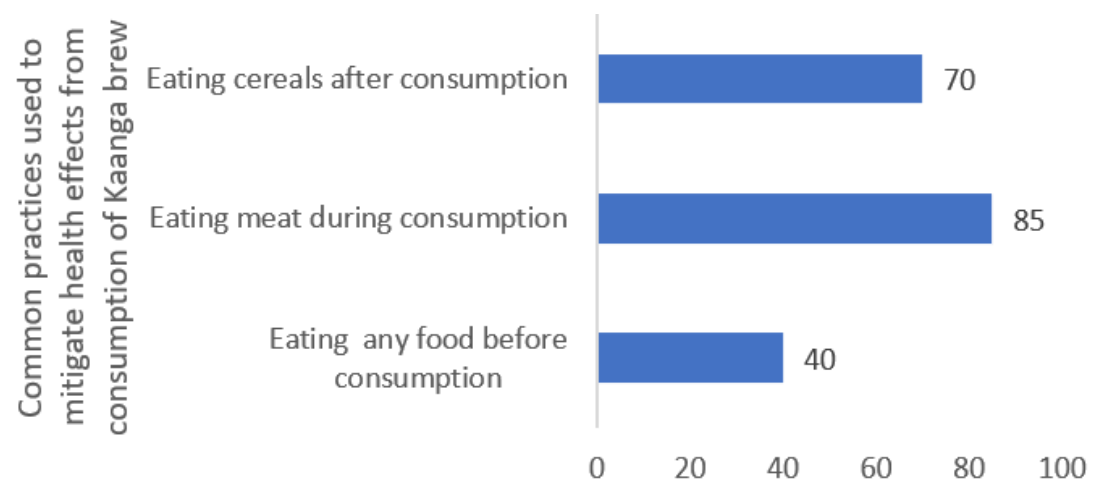

Probability of mitigation (\%)

(b)

Figure 6. Common brews in Meru county with chances of health effect (a) and some of their common mitigation measures (b)

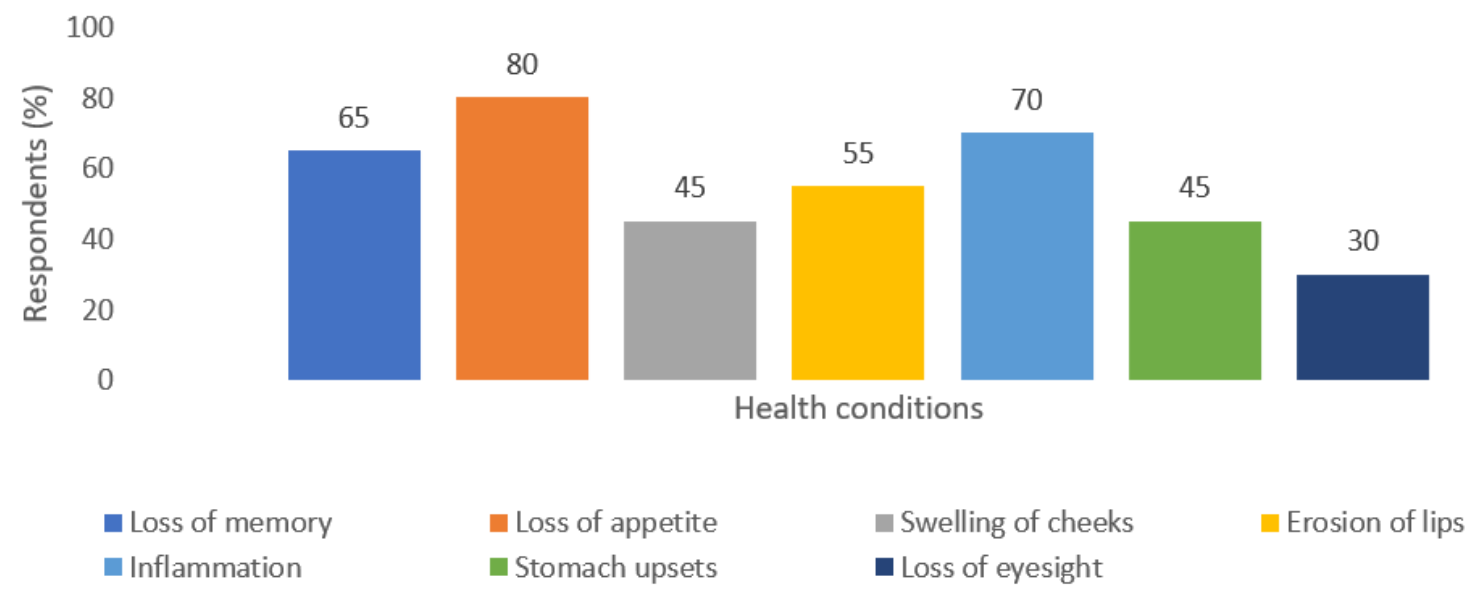

Figure 7. Health effects that result from consuming Kaanga beer

weakening their bodies. $30 \%$ of the respondents had witnessed people lose their vision after consuming the brew. This is attributed to high methanol doses in the brew, especially for the 'stronger' brand of Kaanga beer. From the questionnaires, $80 \%$ of the respondents had witnessed or heard of death cases arising from consuming Kaanga beer. In $60 \%$ of these cases, the victims had complained of loss of eyesight before succumbing to death.

\section{CONCLUSIONS}

Most natives preferred Kaanga brew over others in Meru county because it was cheap and could be obtained on credit.
The additives used in preparing the brew were quite toxic and added in unstandardized ratios. The consumption trend indicated that Kaanga brew is likely to persist in the region thus affecting public health for a long duration. Kaanga brew was alleged to have cause numerous social consequences which affected the public health of the consumers and their families. The brew had significantly higher $(\mathrm{P}>0.05)$ chances of causing health side effects compared to other alcoholic beverages in Meru county. Some of the direct health complications reported from consuming this brew include; loss of vision, memory and appetite, inflammation and stomach upsets. $80 \%$ of the respondents had witnessed or heard of people who had succumbed from drinking Kaanga brew. Kaanga brew was thus confirmed to be a public health 
menace in Meru county. Some of the social effects incurred by family members have long lasting health effects on their mental and reproductive health. It is therefore quite significant that local authorities move with speed to curb the issue before it is out of control.

\section{RECOMMENDATIONS}

The authors recommend more censoring and licensing of Kaanga brew by the concerned local administrators. This will ensure that the brew is standardized to eliminate hazardous compounds. More public health education and campaigns against the brew should be done. The residents should be made fully aware of the side-effects of Kaanga brew. The local administrative should also be stricter in regulation of activities taking place in the drinking dens.

\section{ACKNOWLEDGEMENTS}

The authors wish to thank all the respondents, translators and research guides who ensured the study was well done and viable findings were obtained.

\section{REFERENCES}

Afeiche, M. C., Williams, P. L., Gaskins, A. J., Mendiola, J., Jørgensen, N., Swan, S. H. and Chavarro, J. E. (2014). Meat intake and reproductive parameters among young men. Epidemiology, 25(3), 323-330. https://doi.org/10.1097/ EDE.0000000000000092

Anand, A. C. and Kalra, S. P. (1996). Benign Strictures of The Gastrointestinal Tract. Medical journal, Armed Forces India, 52(4), 215-216. https://doi.org/10.1016/S0377-1237(17) 30868-7

Baker L. B. (2019). Physiology of sweat gland function: The roles of sweating and sweat composition in human health. Temperature, 6(3), 211-259. https://doi.org/10.1080/ 23328940.2019.1632145

Brenna, J. T., Akomo, P., Bahwere, P., Berkley, J. A., Calder, P. C., Jones, K. D., Liu, L., Manary, M., Trehan, I. and Briend, A. (2015). Balancing omega- 6 and omega-3 fatty acids in ready-to-use therapeutic foods (RUTF). BMC medicine, 13, 117. https://doi.org/10.1186/s12916-015-0352-1

Bruha, R., Dvorak, K. and Petrtyl, J. (2012). Alcoholic liver disease. World journal of hepatology, 4(3), 81-90. https://doi.org/10.4254/wjh.v4.i3.81

Burbige, E. J., Lewis, D. R., Jr and Halsted, C. H. (1984). Alcohol and the gastrointestinal tract. The Medical clinics of North America, 68(1), 77-89. https://doi.org/10.1016/s00257125(16)31242-1

Chen, L., Deng, H., Cui, H., Fang, J., Zuo, Z., Deng, J., Li, Y., Wang, X. and Zhao, L. (2017). Inflammatory responses and inflammation-associated diseases in organs. Oncotarget, 9(6), 7204-7218. https://doi.org/10.18632/oncotarget. 23208
Chen, S. H., Wang, J. W. and Li, Y. M. (2010). Is alcohol consumption associated with gastroesophageal reflux disease? Journal of Zhejiang University. Science. B, 11(6), 423-428. https://doi.org/10.1631/jzus.B1000013

Coussens, L. M. and Werb, Z. (2002). Inflammation and cancer. Nature, 420(6917), 860-867. https://doi.org/10.1038/ nature 01322

Ferré, S. and O’Brien, M. C. (2011). Alcohol and Caffeine: The Perfect Storm. Journal of caffeine research, 1(3), 153-162. https://doi.org/10.1089/jcr.2011.0017

Fischer M. H. (1905). The Toxic Effects of Formaldehyde and Formalin. The Journal of experimental medicine, 6(4-6), 487518. https://doi.org/10.1084/jem.6.4-6.487

Gordon H. (2001). Detection of alcoholic liver disease. World journal of gastroenterology, 7(3), 297-302. https://doi.org/ 10.3748/wjg.v7.i3.297

Huang, L., Yi-Chun, M., Changhe, Z., Qiang, W., Xiao-Nan, Z. \& Ji-Dong, L. (2012) Manganese Dioxide Supported on Aluminum Silicate: A New Reagent for Oxidation of Alcohols Under Heterogeneous Conditions. Synthetic Communications, 42(22), 3377-3382. https://doi.org/ 10.1080/00397911.2011.582596

Humia, B. V., Santos, K. S., Barbosa, A. M., Sawata, M., Mendonça, M. and Padilha, F. F. (2019). Beer Molecules and Its Sensory and Biological Properties: A Review. Molecules, 24(8), 1568. https://doi.org/10.3390/molecules24081568

Iglesias, A., Pascoal, A., Choupina, A. B., Carvalho, C. A., Feás, X. and Estevinho, L. M. (2014). Developments in the fermentation process and quality improvement strategies for mead production. Molecules, 19(8), 12577-12590. https://doi.org/10.3390/molecules190812577

Inoue, T., Nagatomi, Y., Uyama, A. and Mochizuki, N. (2013). Degradation of aflatoxin B1 during the fermentation of alcoholic beverages. Toxins, 5(7), 1219-1229. https://doi.org/10.3390/toxins5071219

Jahan, K., Mahmood, D. and Fahim, M. (2015). Effects of methanol in blood pressure and heart rate in the rat. Journal of pharmacy \& bioallied sciences, 7(1), 60-64. https://doi.org/10.4103/0975-7406.148747

Jaishankar, M., Tseten, T., Anbalagan, N., Mathew, B. B. and Beeregowda, K. N. (2014). Toxicity, mechanism and health effects of some heavy metals. Interdisciplinary toxicology, 7(2), 60-72. https://doi.org/10.2478/intox-2014-0009

Kigen, G., Busakhala, N., Kamuren, Z., Rono, H., Kimalat, W. and Njiru, E. (2017). Factors associated with the high prevalence of oesophageal cancer in Western Kenya: a review. Infectious agents and cancer, 12, 59. https://doi.org/10.1186/s13027-017-0169-y

Klinkenberg, J. L. and Hartwig, J. F. (2011). Catalytic organometallic reactions of ammonia. Angewandte Chemie (International ed. in English), 50(1), 86-95. https://doi.org/10.1002/anie.201002354

Kourkouta, L. and Papathanasiou, I. V. (2014). Communication in nursing practice. Materia socio-medica, 26(1), 65-67. https://doi.org/10.5455/msm.2014.26.65-67 
Kumar, A. K. and Sharma, S. (2017). Recent updates on different methods of pretreatment of lignocellulosic feedstocks: a review. Bioresources and bioprocessing, 4(1), 7. https://doi.org/10.1186/s40643-017-0137-9

Learn.e-Limu.org (2020). E-Limu Counties in Kenya. Available at: http://learn.e-limu.org/topic/view/?c=468\&t=1511 (Accessed: 6 July 2020).

Luu, B. N., Nguyen, T. T. and Newman, I. M. (2014). Traditional alcohol production and use in three provinces in Vietnam: an ethnographic exploration of health benefits and risks. BMC Public Health, 14, 731. https://doi.org/10.1186/14712458-14-731

Manuchehri, A. A., Alijanpour, E., Daghmechi, M., Ghaeminan, N., Abedi, S. H., Nikbakhsh, N., Ghazi Mir Saeed, S. A. and Amani, N. (2015). A case of methanol poisoning leading to prolonged respirator dependency with consequent blindness and irreversible brain damage. Caspian journal of internal medicine, 6(3), 180-183.

Mariotti A. (2015). The effects of chronic stress on health: new insights into the molecular mechanisms of brain-body communication. Future science OA, 1(3), FSO23. https://doi.org/10.4155/fso.15.21

Meru.go.ke (2020). Discover Meru County/Meru County Government. Available at: http://meru.go.ke/content.php? com=5\&com2=23\&item=93 (Accessed: 5 July 2020).

Mika, S. and Kazushige, T. (2011). The scent of disease: volatile organic compounds of the human body related to disease and disorder. The Journal of Biochemistry, 150(3), 257-266, https://doi.org/10.1093/jb/mvr090

Noor, M., Hawari, J. and Mokhtar, R. (2020). Methanol outbreak: a Malaysian tertiary hospital experience. Int J Emerg Med, 13, 6. https://doi.org/10.1186/s12245-0200264-5

Obad, A., Peeran, A., Little, J. I., Haddad, G. E. and Tarzami, S. T. (2018). Alcohol-Mediated Organ Damages: Heart and Brain. Frontiers in pharmacology, 9, 81. https://doi.org/10.3389/fphar.2018.00081

Ohimain, E. I. (2016). Methanol contamination in traditionally fermented alcoholic beverages: the microbial dimension. SpringerPlus, 5(1), 1607. https://doi.org/10.1186/s40064016-3303-1

Okaru, A. O., Abuga, K. O., Kibwage, I. O. and Lachenmeier, D. W. (2017). High Ethanol Contents of Spirit Drinks in Kibera Slums, Kenya: Implications for Public Health. Foods (Basel, Switzerland), 6(10), $89 . \quad$ https://doi.org/10.3390/ foods6100089

Oriez, V., Peydecastaing, J. and Pontalier, P. Y. (2019). Lignocellulosic Biomass Fractionation by Mineral Acids and Resulting Extract Purification Processes: Conditions, Yields, and Purities. Molecules, 24(23), 4273. https://doi.org/10.3390/molecules24234273

Papas, R. K., Sidle, J. E., Wamalwa, E. S., Okumu, T. O., Bryant, K. L. ... and Justice, A. C. (2010). Estimating alcohol content of traditional brew in Western Kenya using culturally relevant methods: the case for cost over volume. AIDS and behavior, 14(4), 836-844. https://doi.org/10.1007/s10461008-9492-z
Paton A. (2005). Alcohol in the body. BMJ (Clinical research ed.), 330(7482), 85-87. https://doi.org/10.1136/bmj.330. 7482.85

Piasecki, T. M., Robertson, B. M. and Epler, A. J. (2010). Hangover and risk for alcohol use disorders: existing evidence and potential mechanisms. Current drug abuse reviews, 3(2), 92-102. https://doi.org/10.2174/ 1874473711003020092

Saini, G. K., Gupta, N. D. and Prabhat, K. C. (2013). Drug addiction and periodontal diseases. Journal of Indian Society of Periodontology, 17(5), 587-591. https://doi.org/10.4103/ 0972-124X.119277

Schuppan, D. and Afdhal, N. H. (2008). Liver cirrhosis. Lancet, 371(9615), 838-851. https://doi.org/10.1016/S01406736(08)60383-9

Shekarchizadeh, H., Khami, M. R., Mohebbi, S. Z., Ekhtiari, H. and Virtanen, J. I. (2013). Oral Health of Drug Abusers: A Review of Health Effects and Care. Iranian journal of public health, 42(9), 929-940.

Short, S. E. and Mollborn, S. (2015). Social Determinants and Health Behaviors: Conceptual Frames and Empirical Advances. Current opinion in psychology, 5, 78-84. https://doi.org/10.1016/j.copsyc.2015.05.002

Singh, N., Baby, D., Rajguru, J. P., Patil, P. B., Thakkannavar, S. S. and Pujari, V. B. (2019). Inflammation and cancer. Annals of African medicine, 18(3), 121-126. https://doi.org/10.4103/aam.aam_56_18

Singh, P., Tyagi, M., Kumar, Y., Gupta, K. K. and Sharma, P. D. (2013). Ocular chemical injuries and their management. Oman journal of ophthalmology, 6(2), 83-86. https://doi.org/10.4103/0974-620X.116624

Sohn J. W. (2015). Network of hypothalamic neurons that control appetite. BMB reports, 48(4), 229-233. https://doi.org/10.5483/bmbrep.2015.48.4.272

Sudhinaraset, M., Wigglesworth, C. and Takeuchi, D. T. (2016). Social and Cultural Contexts of Alcohol Use: Influences in a Social-Ecological Framework. Alcohol research: current reviews, 38(1), 35-45.

Suiryanrayna, M. V. and Ramana, J. V. (2015). A review of the effects of dietary organic acids fed to swine. Journal of animal science and biotechnology, 6, 45. https://doi.org/10.1186/s40104-015-0042-z

Sullivan, E. V., Harris, R. A. and Pfefferbaum, A. (2010). Alcohol's effects on brain and behavior. Alcohol research \& health: the journal of the National Institute on Alcohol Abuse and Alcoholism, 33(1-2), 127-143.

Takahashi, R., Wilunda, C., Magutah, K., MwauraTenambergen, W., Wilunda, B. and Perngparn, U. (2017). Correlates of alcohol consumption in rural western Kenya: A cross-sectional study. BMC psychiatry, 17(1), 175. https://doi.org/10.1186/s12888-017-1344-9

Tchounwou, P. B., Yedjou, C. G., Patlolla, A. K. and Sutton, D. J. (2012). Heavy metal toxicity and the environment. Experientia supplementum (2012), 101, 133-164. https://doi.org/10.1007/978-3-7643-8340-4_6 
Tulashie, S. K., Appiah, A. P. and Torku, G. D. (2017). Determination of methanol and ethanol concentrations in local and foreign alcoholic drinks and food products (Banku, Ga kenkey, Fante kenkey and Hausa koko) in Ghana. Food Contamination 4, 14. https://doi.org/ 10.1186/s40550-017-0059-5

Woteki, C. E. and Thomas, P. R. (1992). Eat for Life: The Food and Nutrition Board's Guide to Reducing Your Risk of Chronic Disease. Washington (DC): National Academies Press (US); 1992. Chapter 9, Alcohol, Other Food Substances, and Chronic Diseases. Available at: https://www.ncbi. nlm.nih.gov/books/NBK235015/
Zamani, N., Rafizadeh, A., Hassanian-Moghaddam, H., Akhavan-Tavakoli, A., Ghorbani-Samin, M., Akhgari, M. and Shariati, S. (2019). Evaluation of methanol content of illegal beverages using GC and an easier modified Chromotropic acid method; a cross sectional study. Substance abuse treatment, prevention, and policy, 14(1), 56. https://doi.org/10.1186/s13011-019-0244-z

Zupančič, G. D., Panjičko, M. and Zelić, B. (2017). Biogas Production from Brewer's Yeast Using an Anaerobic Sequencing Batch Reactor. Food technology and biotechnology, 55(2), 187-196. https://doi.org/10.17113/ ftb.55.02.17.5080 


\section{APPENDIX}

\section{Questionnaire}

Hello? My name is . Together with my colleagues from Maasai mara university, we are carrying out a research to determine the health impacts of Kaanga traditional brew on public health. The findings will go a long way in guiding policy makers on the way forward. Kindly collaborate with us by providing truthful responses. We promise to maintain utmost confidentiality in the responses you will give.

Date: Sign:

\section{BIODATA}

Name:

Age:

Sub-County: [Timau] [Meru] [Kianjai] [Maua] [Nkubu] (Please tick $\checkmark$ where appropriate)

Are you a: [Brewer/Pub attendant] or [Customer]? (Please tick $\checkmark$ where appropriate)

\section{INFORMATION REGARDING KAANGA BREW \& PUBLIC HEALTH}

1. What are the factors that make you prefer this brew over others?
a) Cost
b) Credit services
c) Duration you are drunk
d) Other (please specify)

2. a) Do you know how the brew is prepared? [Yes] [No]

b) Can you briefly describe the process?

3. What additives are involved in preparation of Kaanga brew? What are their roles?

4. For how long have you been consuming this brew?

5. a) Are there types of Kaanga brand? [Yes] [No]

b) If YES, what properties discern the different types above?

6. a) Has Kaanga brew affected you (and your family's) social life in any way? [Yes][No]

b) If YES, how?
i) Family wrangles
ii) Use of vulgar language
iii) Violation of conjugal rights
iv) Other (Please explain)

(Please tick $\checkmark$ all that apply)

7. Which types of alcoholic beverages have affected your health (or that of someone you know closely)?

8. What are some of the mitigation measures you take to minimize these health effects?

9. Please name some of the direct health effects that you acquire after consumption of Kaanga brew.

10. Do you know of someone who have died of consuming this brew? 